\title{
Comparative Biomechanics of Thick Filaments and Thin Filaments with Functional Consequences for Muscle Contraction
}

\author{
Mark S. Miller, ${ }^{1}$ Bertrand C. W. Tanner, ${ }^{1}$ Lori R. Nyland, ${ }^{1}$ and Jim O. Vigoreaux ${ }^{1,2}$ \\ ${ }^{1}$ Department of Molecular Physiology \& Biophysics, University of Vermont, Burlington, VT 05405, USA \\ ${ }^{2}$ Department of Biology, University of Vermont, Burlington, VT 05405, USA \\ Correspondence should be addressed to Jim O. Vigoreaux, jvigorea@uvm.edu
}

Received 29 January 2010; Accepted 26 March 2010

Academic Editor: Guy M. Benian

Copyright ( $) 2010$ Mark S. Miller et al. This is an open access article distributed under the Creative Commons Attribution License, which permits unrestricted use, distribution, and reproduction in any medium, provided the original work is properly cited.

\begin{abstract}
The scaffold of striated muscle is predominantly comprised of myosin and actin polymers known as thick filaments and thin filaments, respectively. The roles these filaments play in muscle contraction are well known, but the extent to which variations in filament mechanical properties influence muscle function is not fully understood. Here we review information on the material properties of thick filaments, thin filaments, and their primary constituents; we also discuss ways in which mechanical properties of filaments impact muscle performance.
\end{abstract}

\section{Introduction}

Muscle is a remarkable and intriguing tissue that performs a broad range of specialized functions. While the mention of muscle may elicit images of physical strength, a quick sampling of the animal world reveals that muscle has extraordinary functional diversity and has evolved to provide power for lifting, speed for rapid locomotion, endurance for sustained activity, ultrafast vibrations for sound production, and braking action for stopping movement. This diversity relies upon muscle's active and passive viscoelastic properties providing a range of mechanical versatility in response to loads or forces that vary with time. Muscle is also a highly structured biological material, where proteins are organized into ordered filament arrays that combine to form successively higher ordered, repeated structures (sarcomeres, myofibrils, fibers, and fascicles). Research into muscle function occurs at nearly all levels of its hierarchical organization: single molecule, cell, whole organ, and organism (Figure 1). Pioneering studies on the mechanism of muscle contraction were conducted primarily at the level of the intact muscle, fiber, and to a lesser extent myofibrils (for review, see [1]). Over the past two decades, research on cellular mechanics, in vitro systems, and single molecules has been the dominant theme. Studies at the intermediate levels of filaments and myofibrils have been less common. Knowledge of the biomechanical properties of filaments is important because they reveal how molecular properties scale up and how bulk properties of muscle fibers are dictated by nanoscale phenomena. Because muscle contraction is not simply the sum of individual motor molecules, understanding the properties at each organizational level is important to fully appreciate the behavior of this complex system.

Structural information has been extremely valuable for interpreting mechanical data. Titin, the large sarcomeric protein that extends from the Z-band to the M-line, provides a case in point, where knowledge of its molecular organization and domain structure expedited understanding of its role as a molecular spring (for review, see [26]). The advent of high-resolution structures of native thin filaments and thick filaments (e.g., see $[27,28]$ ) provides an ideal opportunity to examine their mechanical properties and elucidate the molecular basis of their passive and active behavior. Here we will review what is known about the biomechanics of thick filaments, thin filaments, and their constituents, while providing a comparison of shared and unique properties among muscle types.

1.1. Functional Models and the Influence of Filament Compliance. Early models of muscle contraction described the mechanism of filament sliding using rigid thin filament and 


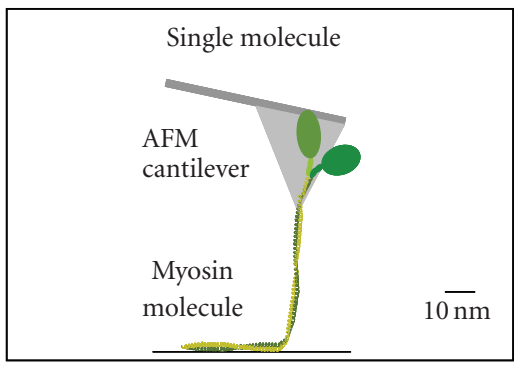

(a)

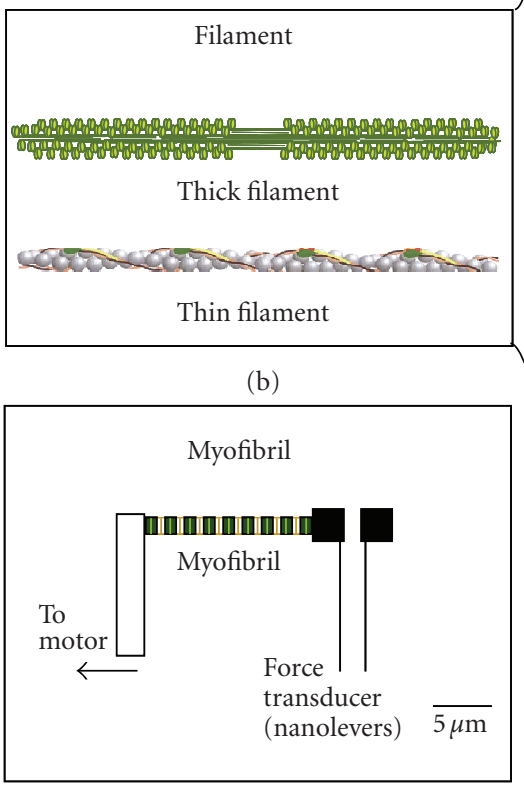

(c)

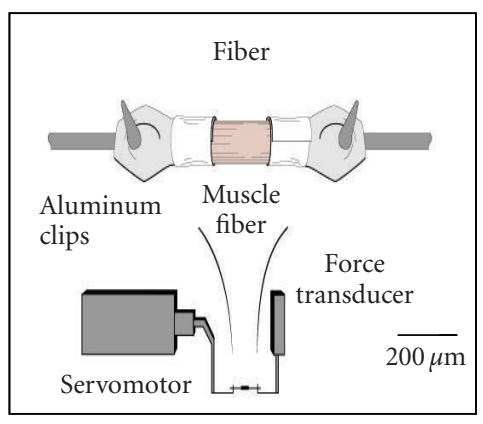

(d)

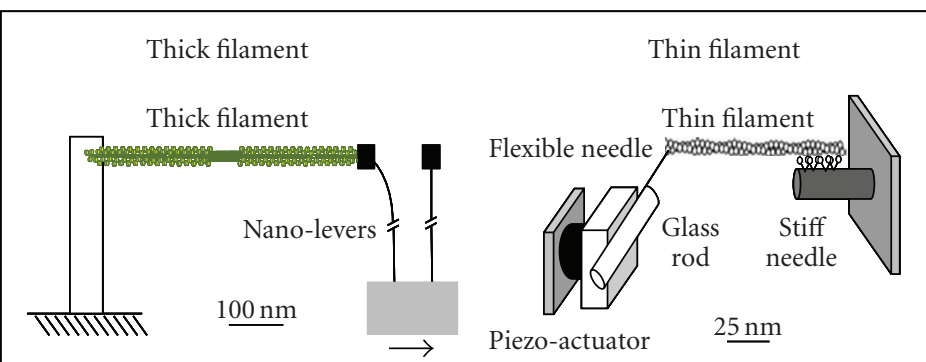

(b1)

(b4)

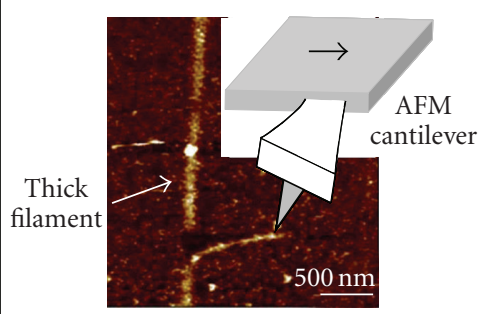

(b2)

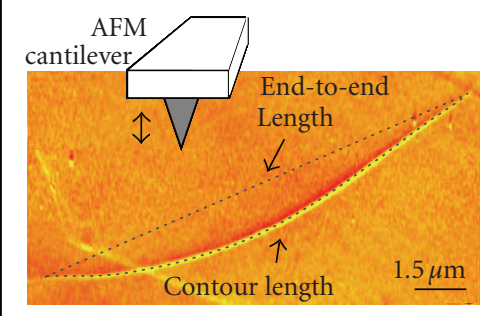

(b3)

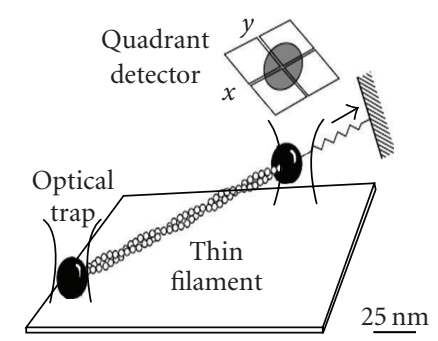

(b5)

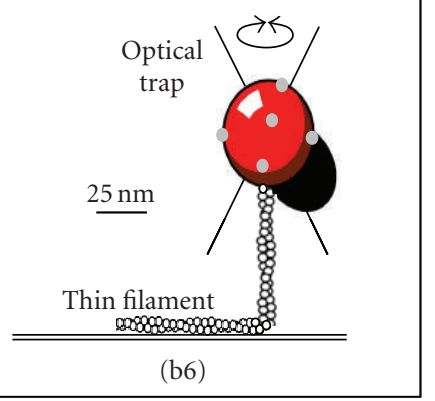

(b6)

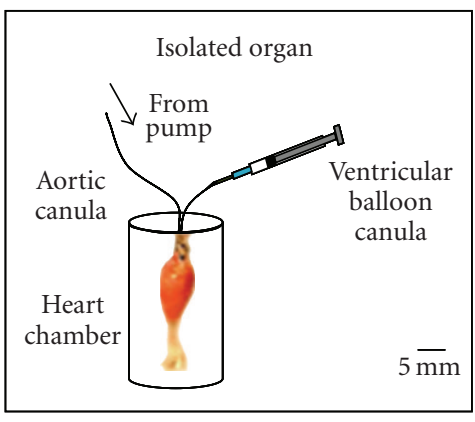

(e)

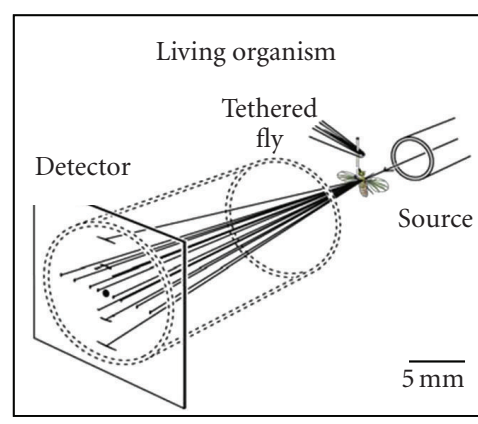

(f)

FIGURE 1: Some approaches used to measure the biomechanical properties of muscle, from single molecules to a living organism. Scale bars are approximate and are based on the size of the preparations, not the equipment. (a) Measurement of axial forces produced when pulling individual myosin molecules [2,3] (figure adapted from [3]). (b) The biomechanical characteristics of thick filaments and thin filaments have been measured with a variety of techniques. (b1) Measurement of elastic properties of thick filaments with cantilevers [4, 5] (figure adapted from [5]). Thin filament elastic properties also have been measured in this way [6]. (b2) Shearing and bending of thick filaments with an AFM probe [7] (figure modified from [7]). (b3) Young's modulus and persistence length of thick filaments calculated from AFM images $[8,9]$ (figure modified from [9]). The persistence length of thin filaments has also been measured by monitoring their thermal fluctuations in shape [10-12]. (b4) Axial stiffness of thin filaments measured with a glass microneedle [13] (figure adapted from [13]). (b5) Flexural rigidity of thin filaments measured in an optical trap [14] (figure modified from [14]). (b6) Torsional rigidity of thin filaments $[15,16]$ (figure adapted from [16]). (c) Axial passive stiffness of myofibrils measured with cantilever force transducers [17-19] (adapted from [17]). (d) Elastic and viscous properties of skinned muscle fibers [20-22]. (e) Elastance of the heart [23, 24]. The scale bar here reflects a mouse heart. (f) X-ray diffraction of live Drosophila flight muscles [25]. 
thick filament backbones, attributing force production and the elastic response of muscle to actin-myosin cross-bridges [29]. Over the past two decades, a number of studies demonstrated that a considerable portion of sarcomere compliance resides in non-cross-bridge structures, revealed by low angle $\mathrm{X}$-ray diffraction measurements of individual fibers [30, 31] and intact tissue within the organism (Figure 1(f)) [25]. Some estimate that approximately half of the sarcomere compliance resides in the thin filaments $[13,32,33]$ and a smaller (20-30\%), but significant, amount resides in the thick filaments [31]. Other studies suggest that the filament contribution to sarcomere elasticity may be much less (1$20 \%)[34,35]$. Nonetheless, these measurements of filament extensibility describe a fundamentally different mechanical system than one with rigid thick filaments and thin filaments, providing an opportunity for investigating the consequently altered mechanisms underlying force production within a lattice of compliant thick filaments and thin filaments.

Recent studies measuring thick filament and thin filament flexibility bestow a striking and fascinating level of complexity at the molecular and cellular level, as hundreds to millions of cross-bridges coordinate to produce force and shortening during muscle contraction. Much of this complexity builds on the behavior outlined by mathematical models of muscle contraction, implementing the well-accepted idea about cross-bridge elasticity being related to cycling kinetics [29, 36-38], although the earliest mathematical models assumed rigid (inextensible) filaments. Extending these ideas about strain-, load-, or positiondependent cross-bridge cycling to the level of filament behavior begins to illustrate that filament extensibility during force development may affect the relative position of actins and myosins along the filaments and the manner by which force is transmitted throughout the filament lattice [39-45].

Even though cross-bridges within a particular muscle likely follow similar chemomechanical processes (or a similar set of rules), filament compliance implies that cross-bridges may not behave identically along the length of a thick filament. As a simple example, consider a compliant thick filament with multiple myosins attached and producing force isometrically (i.e., in the absence of filament sliding) with a compliant thin filament. As these myosins produce greater and greater levels of force, the myosins and myosin binding sites along the actin filament will realign, changing their positions because the thick filaments and thin filaments are stretching in opposite directions towards the Z-band and Mline, respectively $[41,43]$. Now imagine a similar situation where the filaments are rigid, resulting in no realignment of myosin and myosin binding sites along the thin filament and no dynamic redistribution of forces along the filament. In contrast, filament compliance permits realignment of actin filaments and myosin heads, along with a dynamic redistribution of forces as cross-bridges cycle. Filament compliance, therefore, alters behavior between cross-bridges because the forces generated by one cross-bridge affect the position and force experienced by its neighboring cross-bridges. This compliance provides a mechanism of cross-bridge recruitment that enhances force production and coordination of cross-bridge turnover [44], which can lead to an increase in force production compared to a system of rigid filaments. The mechanisms underlying force production become even more intriguing when one envisions the molecular behavior associated with shortening and lengthening transients during normal contraction in the heart, skeletal, or insect flight muscles. For instance, coordinated mechanical and X-ray measurements using intact fibers show that muscle stiffness increases with a $2-6 \mathrm{~nm}$ stretch during tetanic contraction, which may be attributed to the attachment of additional myosin cross-bridge heads [46].

The elastic properties of filaments potentially influence how a striated muscle responds to stretch. Stretching of skeletal muscle results in a decrease in myosin ATPase and a braking action that is largely attributed to the attachment of the second myosin head of a dimer, which implies the attached motor acts as a strain sensor that detects the external stretch and recruits the attachment of its partner [46]. Recruitment of the second motor suggests a mechanical coupling between the two heads and/or a possible role for the rod in modulating motor activity, which may depend upon different mechanical properties of the filaments or regions of myosin $[2,47]$. Conversely, stretching an insect flight muscle (and to some extent, cardiac muscle) leads to an increase in myosin ATPase activity and a delayed rise in tension [48]. Recent models suggest that activation by stretch (and high calcium) may be the result of breaking ATPase inhibiting interhead interactions [49]. The distinct response of the motors to stretch in skeletal versus insect flight muscle may result from differences in how they perceive tension, or the extent to which the filaments are strained and transmit tension to the heads. Regardless of the mechanism, differences in the mechanical behavior of thick filaments and thin filaments in different muscle types may modulate their distinct responses.

While the consequences of filament compliance on crossbridge behavior have been largely illustrated through computational studies [40-45, 50], these studies illustrate the complex protein dynamics that likely exist for a myriad of cellular processes coordinating piconewton forces and nanometer motions among multiple proteins. These models have scaled up from a population of myosins along a single thick filament and thin filament pair $[41,43]$, to multiple filaments [42, $44,50]$, and to a recent study probing the coordinated behavior of multiple sarcomeres [51]. In summary, these models indicate that filament compliance can lead to greater recruitment of force-bearing cross-bridges, and that the level of force produced by the muscle depends upon the relative stiffnesses of thick filaments, thin filaments, and crossbridges. Filament compliance may also affect the overall rate of force development by modulating the force transmitted from cross-bridges into the myofilament lattice, where a more compliant lattice leads to decreased rates of force development $[39,43]$, in agreement with recent experimental results [52]. These models increasingly demonstrate that muscle is a classic example of a complex system stemming from coordinated behavior of cross-bridges, filaments, and sarcomeres to produce a complicated response from a set of rules $[44,51]$. Advancements in computational resources, rapid data acquisition, and massive data storage increase the 
feasibility of novel and important experiments probing and illustrating the molecular mechanisms responsible for this complicated behavior underlying muscle contraction.

\section{Filament Biomechanics}

2.1. Thick Filaments. Unlike thin filaments, the structure and molecular composition of thick filaments is quite diverse, especially among nonvertebrate species. In this group, thick filaments can have a hollow or solid core, single or multiple myosin isoforms, a low-to-high content of the core protein paramyosin [53], and distinct myosin associated proteins uniquely coupled with specific muscle types (for reviews, see [54-56]). Differences in molecular composition dictate structure and mechanical behavior but little is known about these differences throughout the nonvertebrate species and the extent to which they influence the contractile properties of muscle. Accumulating evidence indicates thick filaments change length under physiological forces (e.g., [25]) and these changes influence contractile properties. In addition, the potential for non-myosin thick filament proteins to influence motor behavior may be greater than previously anticipated, meaning functional alterations to muscle contraction may be accomplished through alterations of nonmyosin proteins that can greatly increase the rate and range of adaptability in muscle.

The major component of most, but not all, thick filaments is myosin II, a dimeric protein characterized by two globular (motor) domains and an alpha-helical coiled-coil tail, or rod domain. Atomic force microscopy (AFM) studies on single myosin (Figure 1(a)) showed that the tail region is elastic [3]. The coiled-coil of rabbit skeletal muscle myosin undergoes a large structural transition at forces between 20 and $25 \mathrm{pN}$ where short coiled-coil segments extend to about two and a half times their original length [3]. These force values are more consistent with estimates for actomyosin rigor bonds $(10-30 \mathrm{pN})$ [57-60]. However, nucleotide state and loading rate also affect actomyosin bond strength, and some actomyosin-ADP bonds appear to rupture at forces higher than those of rigor bonds [60]. These single molecule measurements reveal some very complicated and interesting mechanochemical behavior that is fundamental to lengthening and shortening kinetics during muscle contraction, where estimated strengths of an actomyosin rigor bond may not set an upper limit on possible load borne by an actomyosin bond.

The structural transition of the coiled-cold is reversible up to $\sim 30 \mathrm{pN}$ on a timescale of less than one second and the refolding of the coiled-coil dissipates no energy [3], that is, the complete mechanical energy absorbed in the stretching cycle is given back during relaxation. The length extension is very close to the expected length difference between a folded coiled-coil and a completely unfolded polypeptide. These results suggest that myosin may be able to unfold and refold within the timescale and force regime of a contracting muscle. The force data was fit to a two-state model of coiledcoil elasticity in which unfolding occurs initially within short segments of the coiled-coil. Thus, local differences in amino acid sequence that influence the strength of the intraand inter-chain interactions determine the rate and energy of unfolding and refolding. This raises the possibility that differences in rod sequences among myosins from different muscle types may be functionally significant in defining rod elasticity. This also may explain why several rod binding proteins (e.g., M-line myomesin [61], A-band titin [62], Aband flightin [63], and C-zone myosin binding protein $\mathrm{C}$ (MyBP-C) [64]) only bind to specific sequences within the light meromyosin (LMM) region despite the high structural homogeneity of the LMM coiled-coil.

Additional observations about the elasticity of the myosin coiled-coil have come from AFM spectra using single rabbit skeletal muscle myosin and several of its proteolytic subfragments (single-headed myosin, myosin rod, S2, and LMM) [2]. All these molecules exhibited a similar force spectra consisting of a rise phase at low $(<15 \mathrm{pN})$ forces, an intermediate $(\sim 15-100 \mathrm{pN})$ plateau phase, and a final exponential phase $(>100 \mathrm{pN})$. The length of the rise phase was shortest in the LMM fragment suggesting that S2, and specifically the hinge connecting S2 and the LMM, is primarily responsible for increasing the length of the rise phase. The results from this study suggest a reversible, force-induced unfolding and extension of the S2 hinge could occur during muscle contraction [2]. It is unclear, however, the extent to which amino acid sequence variation in the S2 hinge region may be exploited to modulate muscle properties. In Drosophila, part of the S2 hinge is encoded by two alternative exons, one expressed in slow (embryonic) muscle and the other expressed in fast (adult jump and flight) muscle. Studies have tested whether the expression of the slow muscle S2 hinge in an otherwise fast muscle myosin affected myofibril [17] and fiber [20] properties. Expression of the slow muscle S2 hinge produced several structural changes, including an increased myosin rod length, A-band length, and sarcomere length [65]. Despite these structural changes, myofibril (Figure 1(c)) and fiber (Figure 1(d)) mechanics showed that passive properties (tension as well as elastic and viscous modulus) were not affected even though the embryonic S2 hinge was predicted to have a higher propensity to form a coiled-coil than the adult S2 hinge. Myosin kinetics under active conditions were altered by changing the S2 hinge and were consistent with this region increasing the length of the myosin rod [20]. These structural and functional changes were manifested at the whole fly level as a decreased wing-beat frequency and flight performance $[20,65]$, providing an example as to how changes at the molecule level can affect performance and function at the whole organism level. Notably, the observed structural changes indicate that the myosin rod plays an important role in thick filament organization during myofibrillogenesis.

Force-extension studies, similar to the AFM work described above, have been conducted with reconstituted myosin filaments (from rabbit psoas muscle) [4] and nonvertebrate (mussel and crab) native filaments [5] using nanofabricated cantilevers (Figure $1(\mathrm{~b} 1)$ ). Force elongation curves for the skeletal myosin filaments showed that stiffness increased with load and the filaments were more compliant 
at low forces. Under load conditions of approximately $100 \mathrm{pN}$ the filaments exhibit an elastic response. Imposed loads between $\sim 240$ and $440 \mathrm{pN}$ resulted in strains of $\sim 1.1$ to $1.5 \%$. These results are consistent with changes in spacing of the $14.3 \mathrm{~nm}$ reflection (i.e., the longitudinal distance between myosin heads) previously reported from real time $\mathrm{X}$-ray diffraction data of actively contracting frog skeletal muscle [30]. In contrast, native thick filaments isolated from blue mussels (Mytylus edulis) and horseshoe crabs (Limulus polyphemus) are substantially more flexible. Blue mussel thick filaments (length: 10 to $50 \mu \mathrm{m}$ ) were elastic up to stretches of $\sim 23 \%$ of the filament length but did not break until stretched 2-3 times the filament length. The much shorter horseshoe crab thick filaments (length: 4 to $5 \mu \mathrm{m}$ ) were elastic up to stretches of $\sim 66 \%$ of the filament length but did not break until stretched 5-6 times the filament length [5]. These large elastic deformations were repeatable, although a significant amount of hysteresis was evident in both filament types. The elastic behavior is produced at low $(\sim 1$ to $10 \mathrm{nN})$ forces that are within the estimated physiological range of tension produced by the thick filaments. As suggested by the single myosin molecule studies, the extensibility of the thick filament at low forces is likely to arise from stretching and uncoiling of segments of the rod domain. In addition, shearing between myosin rods is likely to contribute to filament elasticity [7].

While the degree to which thick filaments deform during contraction is difficult to quantify, there is evidence suggesting Limulus thick filaments undergo large changes in length during contraction [66]. Using Mytilus thick filaments, length changes were found to occur in steps of $2.7 \mathrm{~nm}$ and integer multiples during lengthening and shortening [67]. The stepwise length change was predicted to occur from the charge distribution along the myosin rod and to contribute to sarcomere length changes and force generation in contracting muscle (see [67] for discussion). Lastly, the yield strength (i.e., the force required to break the filament) of Mytilus thick filaments was not much higher than the estimated physiological force suggesting that the force range experienced by these filaments in vivo is rather narrow. Interestingly, the yield strength of Drosophila flight muscle thick filaments $(\sim 8-17 \mathrm{nN})$, measured by stretching filaments with an AFM tip [7] (Figure 1(b2)), is comparable to that of horseshoe $\mathrm{crab}(\sim 7 \mathrm{nN})$ and mussel $(\sim 18 \mathrm{nN})$, suggesting that regardless of their molecular composition, the upper limit yield strength of thick filaments may not exceed $20 \mathrm{nN}$. In summary, the piconewton forces produced by multiple actomyosin interactions per thick filament produce the requisite forces to produce nanometer deformations of thick filaments, but are likely much too small to compromise the structural integrity of native filaments. These studies provide evidence that thick filament extensibility is part of muscle contraction across a wide range of species.

The greater extensibility of the blue mussel and horseshoe crab thick filaments mentioned above may result from their high content of paramyosin (and high paramyosin to myosin ratio) when compared to thick filaments from vertebrate muscle (which lack paramyosin) or Drosophila indirect flight muscle (IFM; which have very low amounts of paramyosin) [68]. Paramyosin is an $\alpha$-helical coiledcoil protein, similar to the myosin rod, that forms a core onto which the myosin molecules pack to form the thick filament [68]. The ability for paramyosin to directly influence filament compliance is supported by the finding that disrupting phosphorylation sites in Drosophila paramyosin reduced IFM myofibril passive elastic modulus by $15 \%$ [17], consistent with a previous study that found similar reductions in passive, active, and rigor fiber stiffness [21]. This relatively large reduction was unexpected given that the major contributor to passive stiffness is the connecting filaments [69], in light of the assumption that thick filaments are more than 15 times stiffer than connecting filaments [17]. One possibility is that paramyosin serves as, or is part of, an anchoring site for connecting filaments on thick filaments. It is interesting to note that thick filaments from non-vertebrate muscles exhibit a wide range of lengths and widths and that the paramyosin to myosin ratio tends to increase proportionally with filament length [53]. The large extensibility of the long $(>4 \mu \mathrm{m})$ non-vertebrate filaments is also consistent with the suggestion that paramyosin directly influences filament stiffness.

Other notable non-myosin thick filament proteins implicated in filament stiffness include MyBP-C in cardiac thick filaments and flightin in IFM thick filaments. MyBP-C, a modular protein consisting of immunoglobulin-like C2-type domains and fibronectin type-III domains, is found in the nine distal stripes of the $\mathrm{C}$-zone region of the cardiac $\mathrm{A}$ band [70]. Early studies demonstrated that MyBP-C considerably stiffened the filament's calculated persistence length (an index of flexural rigidity) from electron micrographs of reconstituted filaments in the presence and absence of MyBP$C$ [71]. The mechanical contribution of these proteins to native thick filament properties has become possible with the availability and viability of mutant flies and transgenic mice, such as the $\mathrm{cMyBP}-\mathrm{C}^{\mathrm{t} / \mathrm{t}}$ mice that fail to express cardiac MyBP-C [72]. Using images obtained by AFM, Nyland et al. calculated the persistence length of native cardiac thick filaments with and without MyBP-C [8] (Table 1 and Figure 1(b3)). Aside from a small but significantly shorter length $(1.48 \pm 0.02 \mu \mathrm{m} \mathrm{t} / \mathrm{t}$ versus $1.56 \pm 0.02 \mu \mathrm{m}+/+)$, thick filaments lacking MyBP-C exhibited an $\sim 40 \%$ reduction in specific persistence length and Young's (elastic) modulus. Furthermore, they showed that filaments lacking MyBP-C had a greater bending propensity throughout the $\mathrm{C}$ zone suggesting that MyBP-C is directly involved in stiffening the filament. The increased compliance of thick filaments lacking MyBP-C may explain why skinned papillary muscle from $\mathrm{t} / \mathrm{t}$ mice showed a $50 \%$ reduction in the stiffness of rigorbridge-attached thick filaments [73] and why hearts from $t / t$ mice exhibited an abbreviated and reduced systolic elastance (Figure 1(e)) [23]. Altogether, these results illustrate the important role of MyBP-C in modulating cardiac output and provide a plausible mechanism for understanding how some MyBP-C mutations may lead to cardiomyopathies.

Drosophila IFM thick filaments have flightin, a protein that is distributed throughout most of the overlap region of the A band [74]. Similar to mice lacking MyBP-C, thick filaments from mutant flies unable to express flightin in 
TABLE 1: Mechanical properties of thick filaments and thin filaments.

\begin{tabular}{|c|c|c|c|c|c|c|}
\hline Filament & Measurement & Method & Muscle Source & $\begin{array}{l}\text { Stiffness } \\
(\mathrm{pN} / \mathrm{nm})\end{array}$ & $\begin{array}{l}\text { Young's } \\
\text { Modulus } \\
(\mathrm{GPa})\end{array}$ & $\begin{array}{c}\text { Persistence } \\
\text { Length } \\
(\mu \mathrm{m})\end{array}$ \\
\hline Thick $^{(\mathrm{a})}$ & Longitudinal stiffness & X-ray diffraction & Frog skeletal & 252 & $1.9[30]$ & 642 \\
\hline Thick $^{(a)}$ & Flexural rigidity & AFM & Mouse cardiac & 165 & 0.8 & $639[8]$ \\
\hline Thick $^{(\mathrm{a})}$ & Flexural rigidity & AFM & Fruit fly IFM & 442 & 3.0 & $1742[9]$ \\
\hline $\operatorname{Actin}^{(\mathrm{b})}$ & Flexural rigidity & thermal fluctuations & Rabbit skeletal & 19 & 0.8 & $9[10]$ \\
\hline $\operatorname{Actin} *(\mathrm{~b})$ & Flexural rigidity & thermal fluctuations & Rabbit skeletal & 37 & 1.5 & $18[10,12]$ \\
\hline Actin*(b) & Longitudinal stiffness & microneedle & Rabbit skeletal & $44[13]$ & 1.8 & 21 \\
\hline $\operatorname{Actin}^{*}+\operatorname{Tm}^{(\mathrm{c})}$ & Longitudinal stiffness & microneedle & Rabbit skeletal & $65[13]$ & 1.3 & 63 \\
\hline $\begin{array}{l}\operatorname{Actin}+\operatorname{Tm}+ \\
\operatorname{Cad}^{(\mathrm{c})}\end{array}$ & Flexural rigidity & thermal fluctuations & $\begin{array}{c}\text { Rabbit skeletal + } \\
\text { turkey gizzard }\end{array}$ & 21 & 0.4 & $20[10]$ \\
\hline $\operatorname{Thin}^{(\mathrm{c})}$ & $\begin{array}{l}\text { Fiber longitudinal } \\
\text { stiffness }\end{array}$ & X-ray diffraction & Frog skeletal & 125 & $2.5[30]$ & 121 \\
\hline $\operatorname{Thin}^{(c)}$ & $\begin{array}{c}\text { Fiber longitudinal } \\
\text { stiffness }\end{array}$ & mechanics & Rabbit skeletal & $46-68[32]$ & $0.9-1.4$ & $44-66$ \\
\hline
\end{tabular}

Measured values are listed in bold, along with the referenced study. Stiffness values represent the spring constant for a filament length (L) of $1000 \mu \mathrm{m}$. To compare between measurements, the calculations for stiffness $(k)$, Young's modulus $(E)$, and persistence length $\left(L_{p}\right)$ required an estimate of filament geometry listed in the footnotes. Otherwise, $E=k L / A_{c}$, where $A_{c}$ is cross-sectional area [13] and $L_{p}=E I / k_{B} T$, where $I$ is the second moment of inertia, $k_{B}$ is the Boltzman constant, and temperature ( $T$ ) was $300 \mathrm{~K}[129]$.

${ }^{\text {(a) }}$ Calculations assumed a solid, cylindrical filament backbone of radius $6.5 \mathrm{~nm}$ for skeletal thick filaments [30] and $8 \mathrm{~nm}$ [130] for cardiac thick filaments. For insect flight muscle filaments, calculations assumed a hollow cylinder with an outer radius of $7.5 \mathrm{~nm}$ and an inner radius of $3 \mathrm{~nm}$ [131].

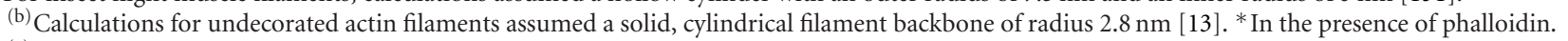

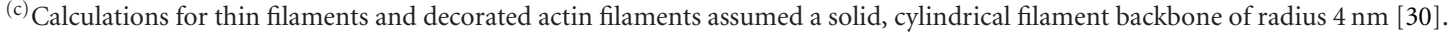

Abbreviations: Tm: Tropomyosin; Cad: Caldesmon; Thin: Native thin filament; Thick: Native thick filament; AFM: Atomic force microscope; IFM: Indirect flight muscles.

their IFM $\left(f \ln ^{0}\right)$ were significantly more compliant and had larger bend angles than their wild-type counterparts [9]. Calculations of persistence length from AFM images between $f l^{0}$ and wild-type filaments from the same age flies revealed that flightin increases total thick filament bending stiffness by $\sim 30-45 \%$, similar to the MyBP-C contribution to cardiac thick filaments [9]. These results are consistent with a model in which flightin (and similarly, MyBP-C) provide lateral reinforcement to the thick filaments via their interaction with a common LMM site $[63,64]$. The existence of connections between myosin rods in Drosophila IFM filaments was further suggested by the shear modulus obtained from bending the filaments with the tip of an AFM cantilever [7]. The values ranged from $3 \mathrm{MPa}$, a value similar to that obtained for purely coiled-coil filaments [75], to $\sim 13 \mathrm{MPa}$. The higher values are thought to arise from the presence of proteins that cross link neighboring coiled-coils. Flightin, along with another A band protein myofilin [76] could fulfill the cross-linking role in Drosophila flight muscles, helping to provide the high stiffness typical of insect flight muscle. The high stiffness of insect flight muscles facilitates stretch activation and the fast oscillatory contraction necessary to beat their wings up to several hundred times per second [48].

The effect of flightin on thick filament mechanics is also clearly manifested at the level of the cell. A comparison of the mechanical properties of skinned flight muscle fibers from $f \ln ^{0}$ and wild-type IFM revealed that passive and dynamic stiffness are reduced by more than $50 \%$ in $f \ln ^{0}$ fibers [22]. This large increase in sarcomere compliance resulted in fibers that absorbed, rather than produced, work. Deficits in whole body locomotion were also evident as flies carrying the flightin mutation were unable to beat their wings and therefore flightless [74]. These studies point to an important role for flightin in reinforcing the structural integrity of the thick filaments and enhancing the production or transmission of force from the cross-bridge to the thorax to elevate flight performance. These studies demonstrate that although thick filament compliance can increase force generation compared to rigid filaments, too much compliance greatly reduces fiber performance and negatively impacts the ability of the animal to move.

Comparing thick filament persistence length between fiber types and species provides an opportunity to examine how the mechanical properties of thick filaments relate to the mechanical performance of the muscle or organ. Persistence length is a commonly used index of the flexibility of a polymer that conveys valuable information about a polymer's mechanical properties. Given that there are different methods of obtaining persistence length, one must keep in mind that differences in values may be the result of variations in assumptions or experimental procedures. Thus, a direct comparison of absolute values obtained by different investigators using various techniques could be misleading and should, at best, be considered as a general approximation. The persistence length values for cardiac thick filaments and IFM thick filaments reported in Table 1 were obtained using a similar AFM approach $[8,9]$, thus a direct comparison is more meaningful in this 
case despite some differences in experimental conditions. The comparison indicates that IFM filaments were almost three times as stiff as cardiac filaments, in proportion to the elastic moduli differences found at the myofibrillar level [18]. The difference in persistence length is quite remarkable especially when one considers the hollow core of the insect flight muscle filaments. While the structure of the insect filaments is not yet known in detail, their extraordinary high stiffness suggests the existence of structures that enhance the rigidity of the myosin rods or that form an inner rigid core. A rigid core consisting of paramyosin filaments held together by cross-linking proteins has been suggested for nematode (C. elegans) body wall thick filaments [71]. However, the persistence length calculated for nematode filaments from electron micrographs is only $\sim 15 \%$ of that calculated for IFM filaments by AFM. In that same study, persistence length calculated for rabbit psoas muscle thick filaments is approximately 25 -fold less than that calculated for frog skeletal muscle from fiber X-ray diffraction studies (Table 1 ). This difference may arise from the use of a methodological approach that relied only on measured contour and endto-end length of the filament [71], rather than the most common and statistically robust approach of measuring filament segments of increasing length $[8,9,77]$. Clearly, an understanding of the experimental techniques and procedures is required to facilitate comparisons within and across different studies. The estimates listed in Table 1 summarize measurements performed under similar conditions wherever possible, and the versatility of persistence length for comparing relative flexibilities of biological polymers and nonbiological materials is demonstrated in Table 2. Interestingly, the bending stiffness of thick filaments is quite large, especially the insect IFM filaments, which are near the range of nanotubes and microtubules (Table 2).

2.2. Thin Filaments. Early studies by Oosawa and colleagues revealed that actin filaments are compliant in vitro as well as in the myofibril, prompting speculation that changes in thin filament length may contribute to muscle contraction [78, 79]. More recent studies using X-ray diffraction of frog sartorius and semitendinosus muscles estimate that $\sim 40-50 \%$ of the sarcomere compliance of actively contracting muscle originates from the thin filaments [30, 31]. Measurements of mechanical compliance in rabbit psoas are consistent with these X-ray studies, showing that thin filaments contribute $\sim 44 \%$ to sarcomere compliance under active conditions [32]. However, one study with carbodiimide-cross-linked rabbit fibers found virtually no compliance in the actin filaments, with all the compliance in the myosin motor domain [34]. Mechanical experiments in frog tibialis anterior muscle suggest a smaller thin filament contribution to the total sarcomere compliance $(\sim 20-29 \%)[35,80]$, an estimate that could be significantly higher if thin filament compliance were nonlinear [35] (thus, more consistent with the values from $\mathrm{X}$-ray studies). Thin filament extensibility was determined to be $\sim 50 \%$ of the sarcomere compliance in active muscle using single actin filaments reconstituted from rabbit psoas tissue [13]. Overall, these studies suggest that the thin filament
TABLE 2: Range of persistence length for biological polymers and nanotubes.

\begin{tabular}{|c|c|c|}
\hline Material & $\begin{array}{l}\text { Persistence } \\
\text { Length } \\
(\mu \mathrm{m})\end{array}$ & Comments and References \\
\hline Silk & 0.0004 & $\begin{array}{l}\text { Recombinant spider dragline silk } \\
\text { nanofibers [132] }\end{array}$ \\
\hline Titin & $0.0007-0.04$ & $\begin{array}{l}\text { For intact (rabbit skeletal) protein, } \\
\text { individual domains, and elastic and } \\
\text { inelastic regions }[133-135]\end{array}$ \\
\hline Hyaluronan & 0.0045 & Articular cartilage [136] \\
\hline Collagen & $\begin{array}{c}0.0112- \\
0.057\end{array}$ & Types I, II, III [136, 137] \\
\hline Projectin & 0.030 & Lethocerus flight muscle [138] \\
\hline Mucins & 0.036 & Human ocular [139] \\
\hline Kettin & 0.045 & Recombinant fragments [138] \\
\hline DNA & 0.053 & $<3000$ bp [140] \\
\hline $\begin{array}{l}\text { Intermediate } \\
\text { filaments }\end{array}$ & 1 & $\begin{array}{l}\text { In vitro polymerized human vimentin } \\
\text { [77] }\end{array}$ \\
\hline Cofilactin & 2.2 & In vitro polymerized [92] \\
\hline Actin & $9.0-17.7$ & $\begin{array}{l}\text { In vitro polymerized with or without } \\
\text { phalloidin }[10,12,92,141]\end{array}$ \\
\hline Nanotubes & $17-32$ & Single walled carbon nanotubes [142] \\
\hline $\begin{array}{l}\text { Flagellar } \\
\text { filaments }\end{array}$ & $2.4-41.1$ & From bacteria [129] \\
\hline $\begin{array}{l}\text { Thin } \\
\text { filaments }\end{array}$ & $44-121$ & See Table 1 \\
\hline $\begin{array}{l}\text { Thick } \\
\text { filaments }\end{array}$ & $27-1742$ & $\begin{array}{l}\text { From various species and muscle types } \\
{[8,9,71]}\end{array}$ \\
\hline Microtubules & $110-5200$ & $\begin{array}{l}\text { In vitro polymerized with taxol or } \\
\text { paclitaxel }[12,141,143]\end{array}$ \\
\hline
\end{tabular}

contributes $\sim 20-50 \%$ to the total sarcomere compliance, indicating that the extension of actin plays a significant role in muscle contraction.

The mechanical properties of reconstituted actin polymers, with and without regulatory proteins, have been studied extensively using a variety of methods. Investigating the mechanical effects of adding different regulatory proteins to bare actin provides insight into the function and performance of the native thin filament. The two primary sources of actin were rabbit $[10,11,13]$ and chicken skeletal muscle [11], with the actin binding proteins being derived from rabbit skeletal muscle $[10,13]$, turkey gizzards (smooth muscle) [10], or other sources [11]. Since actin and regulatory proteins are highly conserved, species differences are seldom considered important even though mutations of single amino acids can considerably affect contractility. Persistence length measurements of fluorescent rhodamineactin filaments indicate that flexural rigidity increases with the addition of tropomyosin alone $[10,11,13]$ and tropomyosin-troponin with or without $\mathrm{Ca}^{2+}[10]$ (Table 1). Isoform specific effects that have been noted in that smooth muscle tropomyosin had a lesser effect on persistence length than skeletal muscle tropomyosin $[10,11]$. The flexural rigidity of actin with tropomyosin-troponin decreased with 
the addition of $\mathrm{Ca}^{2+}$, remaining above that of actin alone, and suggests that thin filaments become more flexible upon activation [10]. The increased compliance may allow for better alignment of actin with the myosin heads, providing more binding sites for myosin compared to a rigid thin filament. Flexural rigidity of fluorescent rhodamine-actin filaments increases with the addition of phalloidin $[10,11]$, a peptide commonly used to stabilize actin filaments, and could therefore significantly affect experimental results when this peptide is present. Notably, studies where phalloidin was added to the actin filaments still indicate significant actin filament compliance using a glass microneedle (Figure 1(b4)) with rabbit actin [13], the optical trap (Figure 1(b5)) with chicken pectoralis [14], and microfabricated cantilevers [6]. Other factors were found not to dramatically affect the longitudinal flexibility of filamentous actin including the presence of metal ions $\mathrm{Mg}^{2+}$ or $\mathrm{Ca}^{2+}$, ionic strength ranging from 5 to $100 \mathrm{mM}$, or whether the filaments were assembled from ADP or ATP monomers [10]. While not explored, posttranslational modification of tropomyosin and other actinbinding proteins may play a role in modulating thin filament mechanical properties.

The torsional rigidity of actin with phalloidin (Figure 1(b6)) was found to be three times higher for bound $\mathrm{Ca}^{2+}$ compared with bound $\mathrm{Mg}^{2+}$ while the flexural rigidity remained unchanged [15]. This raises the possibility that these cations, as well as myosin binding, may influence thin filament properties, potentially promoting more effective muscle contraction by modulating the torsional rigidity of the filaments [81]. Other studies show actin filaments with phalloidin to be more flexible and less durable in torsion, compared to bending or stretching $[16,82]$. Thus, changes in the twist of the actin helix resulting from the attachment of cross-bridges may propogate considerable distances along the filament, contributing to a suite of cooperative mechanisms that coordinate or amplify active force generation [83-86].

Phosphorylation may also play an important role in regulating actin filament stiffness. An actin-binding C terminal fragment of caldesmon, a protein that regulates smooth muscle contraction through its binding to actin, myosin and tropomyosin [87], increases persistence length in a phosphorylation-dependent manner [11]. Phosphorylation of tropomyosin at Ser 283 (the second-to-last residue at the C-terminus) has been shown to increase the strength of the tropomyosin head-to-tail interaction and the tropomyosin-troponin $\mathrm{T}$ interaction, and may also modulate tropomyosin's affinity for actin [88, 89]. Other studies have shown that tropomyosin phosphorylation is essential for long range cooperative activation along the thin filament [90]. Whether this phosphorylation effect is achieved through changes in thin filament mechanical properties remains to be established.

In contrast to most actin binding proteins that increase filament radius and mass, cofilin, a protein known to sever actin filaments, decreases actin filament torsional [91] and flexural rigidity [92], reflected as a fivefold decrease in persistence length. Cofilin reduces stiffness by changing the filament elasticity and geometry, hypothetically through a reorganization of the actin subdomain 2 [92]. Similarly, formins, a family of proteins that are associated with the polymerization of actin, decrease the flexural rigidity of actin filaments, suggesting these proteins regulate actin filament conformation and may affect the ability of actin binding proteins to attach [93]. While these actin binding proteins do not participate in muscle contraction, understanding their effects increases our knowledge of thin filament mechanics and may lead to important discoveries surrounding myofibrillogenesis and/or repair mechanisms.

2.3. Other Sarcomeric Structures. The extent to which thin filament and thick filament compliance contributes to active force production in vivo is likely determined by the nature of their connections to, and the properties of, other sarcomeric structures, namely Z-bands, M-bands and filaments of nebulin (a large modular actin binding protein with multiple functions [94]), titin, and related proteins (e.g., the connecting filament proteins kettin and projectin that in insect flight muscle connect the thick filaments to the Z-line [95]). Many studies have examined the mechanical behavior of several of these individual components (for reviews, see [96-98]) but a limited number of studies have explored whether there is a correlation between fiber type and expression of specific isoform sets among these different elastic structures (e.g., [99]). Despite these efforts, we lack a general understanding of how individual component properties are related to those of other sarcomeric components or how, for example, the expression of titin length isoforms in a particular fiber type is tuned mechanically to the molecular composition of the thick filament and its mechanical capabilities. These relationships may play a significant role in the developing heart and diseased heart, where shifts in titin isoforms are correlated with changes in cardiac output [100-102]. Similarly, the relation between connecting filament (kettin and projectin) isoforms and thick filament composition in insect flight muscle is likely to be significant given the large contribution of the connecting filaments to active properties in this muscle type $[69,103]$.

\subsection{Open Questions, Interpretations, and Future Studies.} Recent studies suggest that the functional unit of contraction is the half-sarcomere [104]. As we inch closer towards elucidating the complete catalogue of proteins that constitute this elaborate structure and a better understanding of their mechanical properties, a clearer picture of the mechanism of muscle contraction will benefit from merging information from bottom-up approaches such as those described here, and the more classical top-down (fiber and muscle mechanical/structural) approaches. The functional significance of filament compliance and its role in the evolutionary divergence of striated muscle remain open questions. As reviewed here, it is becoming increasingly clear that from a mechanical perspective, all thin filaments and thick filaments are not created equal and that large differences exist among thick filaments from different muscle types. We envision multiple possibilities, not mutually exclusive, for 
how filament compliance could come into play in defining the functional properties of muscle.

(i) Filament strain and stiffness influence the placement of myosin heads along the thin filament with implications for cooperative activation, regulatory mechanisms, and overall force production. A compliant filament (both longitudinal and torsional) may expand the axial range for myosin motors to find target zones along actin, increasing the probability of cross-bridge binding. These processes may be modulated by the number of actins exposed along the thin filament, following $\mathrm{Ca}^{2+}$ activation of the troponin/tropomyosin complex, differentially affecting contractile dynamics on a twitchto-twitch or beat-to-beat basis depending upon muscle type [105-107]. While stretch activation is present in all muscles (where force transiently increases to a greater level following a stretch), its affects most strongly impact oscillatory muscle systems that are constantly undergoing length changes, such as in insect flight muscle or cardiac muscle. Although not completely understood, these cooperative mechanisms involving the spatial and mechanical properties of the filaments and cross-bridges may fundamentally underlie the Frank-Starling relationship in the heart [108].

(ii) Thick filament stiffness and/or strain influence the orientation and kinetic properties of the motor domain. Significant myosin loss has been found with aging [109], cancer [110], heart failure [111-113], chronic obstructive pulmonary disease [114], acute quadriplegia [115], and severe spinal injury [116]. The myofibrillar protein loss appears to be specific for myosin as several studies have shown no alterations in other proteins, such as actin. This loss of myosin may increase thick filament strain through a reduction of thick filament stiffness and/or decrease thin filament and thick filament strain since the number of heads available for binding are reduced. The modulation of thick filament and thin filament strain could lead to alterations in myosin kinetics, as suggested by recent work in heart failure patients [112]. Although not directly measured, orientation changes in the myosin head relative to actin via thick filament strain have been suggested by experiments in insects to explain changes in passive and active fiber properties due to sarcomere lengthening [103] and aging [117]. Thus, altering thick filament stiffness may be a means of regulating fiber contractile properties; whether this result is a consequence of aging and/or disease or is an adaptation to these specific conditions is still unknown.

(iii) Filament stiffness defines muscle's ability to recycle energy, for example, in the form of elastic recoil in oscillatory systems such as the vertebrate heart and the insect flight muscle. Flying insects rely on elastic recoil to lower the energetic cost of flight [118]. The extent to which an insect relies on muscle to store elastic energy for inertial work depends on its size, wing beat frequency and mode of operation (i.e., synchronous versus asynchronous) [119]. Varying the stiffness of the thoracic musculature, via the stiffness of its underlying filaments, may be one way mother nature adjusts to the challenge of energetically expensive locomotive activities.

(iv) Filament stiffness influences muscle performance by defining the effective transmission of actomyosin forces to end-connecting structures. Increasing evidence points to the Z-band (and to a lesser extent the M-line) as the nexus of signaling pathways that define the muscle's short- and longterm response to physiological demand [120-122]. Sensitive stress or strain sensors reside in the Z-band, particularly in cardiac muscle, where they integrate and coordinate the responses to internal and external mechanical signals. Mutations and genetic polymorphisms in several Z-band associated proteins have been implicated in adaptive and maladaptive remodeling via complex, mechanically activated cell signaling events whose details are just beginning to be elucidated [120]. More studies are needed to identify how differences in the mechanical properties of thin filaments and thick filaments are interpreted by the elaborate sensing and signaling complexes that reside in the Z-bands and M-lines.

(v) Filament stiffness and the corresponding strains induced during muscle contraction promote sarcomeric stability and influence muscle's ability to sustain external forces or repetitive cycles of high force. An extreme example is seen in Drosophila IFM where the absence of flightin leads to decreased thick filament stiffness and stability and complete loss of muscle's ability to sustain force $[9,74,123]$. Another example in skeletal muscles is that fast contracting fibers are more easily damaged with large external forces [124] and have increased sarcomere disarray and greater force reduction after multiple contractions, especially near physiological temperatures [125], compared to slow oxidative fibers. These skeletal muscle fiber type differences in stability may be due to different loads being transmitted to the thick filaments during high force or repetitive loading given that skeletal muscles express different proteins in the M-line [126] and Z-band [97, 120], as well as different isoforms of titin [99] based upon the type of myosin heavy chain (MHC) expressed (e.g., MHC I or slow contracting versus MHC IIA or fast contracting). In addition, thick filament stiffness may be altered with fiber type due to different intramolecular interactions between myosin rods because of their varying amino acid sequences [127]. In summary, the thick filaments from different fiber types may vary in their stiffness and the forces experienced during loading, altering their stability and susceptibility to damage.

(vi) The mechanical properties of the filaments may influence how they align during myofibrillogenesis, and whether the resulting structure is a simple lattice or a superlattice [128].

This list of possibilities is by no means exhaustive and many important questions remain to be answered. As we learn more about the molecular composition and structure of filaments from different muscle types and apply some of the aforementioned techniques to elucidate their material properties and those of their underlying components, we will improve our understanding of the microscopic principles that quantitatively and qualitatively define the salient features of muscle and gain an appreciation for the remarkable versatility of this most amazing machina carnis. This, in turn, will contribute to our knowledge of the evolution of muscle, its capacity for adaptation, and susceptibility to disease, and open doors for using muscle filaments as a paradigm for biologically inspired materials. 


\section{Acknowledgments}

M. S. Miller, B. C. W. Tanner, and L. R. Nyland contributed equally to this paper. The authors thank members of the Vigoreaux laboratory for helpful comments. They acknowledge the following support: NSF IOS-0718417 to J. O. Vigoreaux, NIH K01 Mentored Research Grant to M. S. Miller (AG-031303), and NSF Postdoctoral Fellowship in Biology to B. C. W. Tanner (DBI-0905830). The content is solely the responsibility of the authors and does not necessarily represent the official view of the National Institute on Aging, National Institutes of Health, or National Science Foundation.

\section{References}

[1] H. E. Huxley, "Fifty years of muscle and the sliding filament hypothesis," European Journal of Biochemistry, vol. 271, no. 8, pp. 1403-1415, 2004.

[2] D. D. Root, V. K. Yadavalli, J. G. Forbes, and K. Wang, "Coiled-coil nanomechanics and uncoiling and unfolding of the superhelix and $\alpha$-helices of myosin," Biophysical Journal, vol. 90, no. 8, pp. 2852-2866, 2006.

[3] I. Schwaiger, C. Sattler, D. R. Hostetter, and M. Rief, "The myosin coiled-coil is a truly elastic protein structure," Nature Materials, vol. 1, no. 4, pp. 232-235, 2002.

[4] D. Dunaway, M. Fauver, and G. Pollack, "Direct measurement of single synthetic vertebrate thick filament elasticity using nanofabricated cantilevers," Biophysical Journal, vol. 82, no. 6, pp. 3128-3133, 2002.

[5] T. Neumann, M. Fauver, and G. H. Pollack, "Elastic properties of isolated thick filaments measured by nanofabricated cantilevers," Biophysical Journal, vol. 75, no. 2, pp. 938-947, 1998.

[6] X. Liu and G. H. Pollack, "Mechanics of F-actin characterized with microfabricated cantilevers," Biophysical Journal, vol. 83, no. 5, pp. 2705-2715, 2002.

[7] L. Kreplak, L. R. Nyland, J. L. Contompasis, and J. O. Vigoreaux, "Nanomechanics of native thick filaments from indirect flight muscles," Journal of Molecular Biology, vol. 386, no. 5, pp. 1403-1410, 2009.

[8] L. R. Nyland, B. M. Palmer, Z. Chen, et al., "Cardiac myosin binding protein- $\mathrm{C}$ is essential for thick-filament stability and flexural rigidity," Biophysical Journal, vol. 96, no. 8, pp. 32733280, 2009.

[9] J. L. Contompasis, L. R. Nyland, D. W. Maughan, and J. O. Vigoreaux, "Flightin is necessary for length determination, structural integrity, and large bending stiffness of insect flight muscle thick filaments," Journal of Molecular Biology, vol. 395, no. 2, pp. 340-348, 2010.

[10] H. Isambert, P. Venier, A. C. Maggs, et al., "Flexibility of actin filaments derived from thermal fluctuations. Effect of bound nucleotide, phalloidin, and muscle regulatory proteins," Journal of Biological Chemistry, vol. 270, no. 19, pp. 11437-11444, 1995.

[11] M. J. Greenberg, C.-L. Wang, W. Lehman, and J. R. Moore, "Modulation of actin mechanics by caldesmon and tropomyosin," Cell Motility and the Cytoskeleton, vol. 65, no. 2, pp. 156-164, 2008.

[12] F. Gittes, B. Mickey, J. Nettleton, and J. Howard, "Flexural rigidity of microtubules and actin filaments measured from thermal fluctuations in shape," Journal of Cell Biology, vol. 120, no. 4, pp. 923-934, 1993.

[13] H. Kojima, A. Ishijima, and T. Yanagida, "Direct measurement of stiffness of single actin filaments with and without tropomyosin by in vitro nanomanipulation," Proceedings of the National Academy of Sciences of the United States of America, vol. 91, no. 26, pp. 12962-12966, 1994.

[14] D. E. Dupuis, W. H. Guilford, J. Wu, and D. M. Warshaw, "Actin filament mechanics in the laser trap," Journal of Muscle Research and Cell Motility, vol. 18, no. 1, pp. 17-30, 1997.

[15] R. Yasuda, H. Miyata, and K. Kinosita Jr., "Direct measurement of the torsional rigidity of single actin filaments," Journal of Molecular Biology, vol. 263, no. 2, pp. 227-236, 1996.

[16] Y. Tsuda, H. Yasutake, A. Ishuima, and T. Yanaogida, "Torsional rigidity of single actin filaments and actin-actin bond breaking force under torsion measured directly by in vitro micromanipulation," Proceedings of the National Academy of Sciences of the United States of America, vol. 93, no. 23, pp. 12937-12942, 1996.

[17] Y. Hao, M. S. Miller, D. M. Swank, et al., "Passive stiffness in Drosophila indirect flight muscle reduced by disrupting paramyosin phosphorylation, but not by embryonic myosin S2 hinge substitution," Biophysical Journal, vol. 91, no. 12, pp. 4500-4506, 2006.

[18] M. Kulke, C. Neagoe, B. Kolmerer, et al., "Kettin, a major source of myofibrillar stiffness in Drosophila indirect flight muscle," Journal of Cell Biology, vol. 154, no. 5, pp. 10451057, 2001.

[19] V. Joumaa, D. E. Rassier, T. R. Leonard, and W. Herzog, "Passive force enhancement in single myofibrils," Pflugers Archiv European Journal of Physiology, vol. 455, no. 2, pp. 367-371, 2007.

[20] M. S. Miller, C. M. Dambacher, A. F. Knowles, et al., "Alternative S2 hinge regions of the myosin rod affect myofibrillar structure and myosin kinetics," Biophysical Journal, vol. 96, no. 10, pp. 4132-4143, 2009.

[21] H. Liu, M. S. Miller, D. M. Swank, W. A. Kronert, D. W. Maughan, and S. I. Bernstein, "Paramyosin phosphorylation site disruption affects indirect flight muscle stiffness and power generation in Drosophila melanogaster," Proceedings of the National Academy of Sciences of the United States of America, vol. 102, no. 30, pp. 10522-10527, 2005.

[22] J. A. Henkin, D. W. Maughan, and J. O. Vigoreaux, "Mutations that affect flightin expression in Drosophila alter the viscoelastic properties of flight muscle fibers," American Journal of Physiology, vol. 286, pp. C65-C72, 2004.

[23] B. M. Palmer, D. Georgakopoulos, P. M. Janssen, et al., "Role of cardiac myosin binding protein $\mathrm{C}$ in sustaining left ventricular systolic stiffening," Circulation Research, vol. 94, no. 9, pp. 1249-1255, 2004.

[24] Y. Araki, A. Usui, O. Kawaguchi, et al., "Pressure-volume relationship in isolated working heart with crystalloid perfusate in swine and imaging the valve motion," European Journal of Cardio-Thoracic Surgery, vol. 28, no. 3, pp. 435-442, 2005.

[25] M. Dickinson, G. Farman, M. Frye, et al., "Molecular dynamics of cyclically contracting insect flight muscle in vivo," Nature, vol. 433, no. 7023, pp. 330-334, 2005.

[26] H. Granzier and S. Labeit, "Structure-function relations of the giant elastic protein titin in striated and smooth muscle cells," Muscle and Nerve, vol. 36, no. 6, pp. 740-755, 2007.

[27] A. Pirani, M. V. Vinogradova, P. M. Curmi, et al., "An atomic model of the thin filament in the relaxed and $\mathrm{Ca}^{2+}$-activated 
states," Journal of Molecular Biology, vol. 357, no. 3, pp. 707717, 2006.

[28] M. E. Zoghbi, J. L. Woodhead, R. L. Moss, and R. Craig, "Three-dimensional structure of vertebrate cardiac muscle myosin filaments," Proceedings of the National Academy of Sciences of the United States of America, vol. 105, no. 7, pp. 2386-2390, 2008.

[29] A. F. Huxley, "Muscle structure and theories of contraction," Progress in Biophysics and Biophysical Chemistry, vol. 7, pp. 255-318, 1957.

[30] H. E. Huxley, A. Stewart, H. Sosa, and T. Irving, "X-ray diffraction measurements of the extensibility of actin and myosin filaments in contracting muscle," Biophysical Journal, vol. 67, no. 6, pp. 2411-2421, 1994.

[31] K. Wakabayashi, Y. Sugimoto, H. Tanaka, Y. Ueno, Y. Takezawa, and Y. Amemiya, "X-ray diffraction evidence for the extensibility of actin and myosin filaments during muscle contraction," Biophysical Journal, vol. 67, no. 6, pp. 24222435, 1994.

[32] H. Higuchi, T. Yanagida, and Y. E. Goldman, "Compliance of thin filaments in skinned fibers of rabbit skeletal muscle," Biophysical Journal, vol. 69, no. 3, pp. 1000-1010, 1995.

[33] Y. E. Goldman and A. F. Huxley, "Actin compliance: are you pulling my chain?" Biophysical Journal, vol. 67, no. 6, pp. 2131-2133, 1994.

[34] K. Tawada and M. Kimura, "Stiffness of carbodiimidecrosslinked glycerinated muscle fibres in rigor and relaxing solutions at high salt concentrations," Journal of Muscle Research and Cell Motility, vol. 7, no. 4, pp. 339-350, 1986.

[35] M. A. Bagni, G. Cecchi, B. Colombini, and F. Colomo, "Sarcomere tension-stiffness relation during the tetanus rise in single frog muscle fibres," Journal of Muscle Research and Cell Motility, vol. 20, no. 5-6, pp. 469-476, 1999.

[36] A. F. Huxley and R. M. Simmons, "Proposed mechanism of force generation in striated muscle," Nature, vol. 233, no. 5321, pp. 533-538, 1971.

[37] E. Eisenberg, T. L. Hill, and Y. Chen, "Cross-bridge model of muscle contraction. Quantitative analysis," Biophysical Journal, vol. 29, no. 2, pp. 195-227, 1980.

[38] E. Pate and R. Cooke, "A model of crossbridge action: the effects of ATP, ADP and Pi," Journal of Muscle Research and Cell Motility, vol. 10, no. 3, pp. 181-196, 1989.

[39] Y. Luo, R. Cooke, and E. Pate, "A model of stress relaxation in cross-bridge systems: effect of a series elastic element," American Journal of Physiology, vol. 265, no. 1, part 1, pp. C279-C288, 1993.

[40] S. M. Mijailovich, J. J. Fredberg, and J. P. Butler, "On the theory of muscle contraction: filament extensibility and the development of isometric force and stiffness," Biophysical Journal, vol. 71, no. 3, pp. 1475-1484, 1996.

[41] T. L. Daniel, A. C. Trimble, and P. B. Chase, "Compliant realignment of binding sites in muscle: transient behavior and mechanical tuning," Biophysical Journal, vol. 74, no. 4, pp. 1611-1621, 1998.

[42] P. B. Chase, J. M. Macpherson, and T. L. Daniel, "A spatially explicit nanomechanical model of the half-sarcomere: myofilament compliance affects $\mathrm{Ca}^{2+}$-activation," Annals of Biomedical Engineering, vol. 32, no. 11, pp. 1559-1568, 2004.

[43] K. S. Campbell, "Filament compliance effects can explain tension overshoots during force development," Biophysical Journal, vol. 91, no. 11, pp. 4102-4109, 2006.

[44] B. C. Tanner, T. L. Daniel, and M. Regnier, "Sarcomere lattice geometry influences cooperative myosin binding in muscle," PLoS Computational Biology, vol. 3, no. 7, article e115, 2007.
[45] A. Vilfan, E. Frey, and F. Schwabl, "Elastically coupled molecular motors," European Physical Journal B, vol. 3, no. 4, pp. 535-546, 1998.

[46] E. Brunello, M. Reconditi, R. Elangovan, et al., "Skeletal muscle resists stretch by rapid binding of the second motor domain of myosin to actin," Proceedings of the National Academy of Sciences of the United States of America, vol. 104, no. 50, pp. 20114-20119, 2007.

[47] D. A. Smith and S. M. Mijailovich, "Toward a unified theory of muscle contraction. II: predictions with the mean-field approximation," Annals of Biomedical Engineering, vol. 36, no. 8, pp. 1353-1371, 2008.

[48] J. W. Pringle, "Stretch activation of muscle: function and mechanism," Proceedings of the Royal Society B, vol. 201, no. 1143, pp. 107-130, 1978.

[49] H. A. Al-Khayat, L. Hudson, M. K. Reedy, T. C. Irving, and J. M. Squire, "Myosin head configuration in relaxed insect flight muscle: X-ray modeled resting cross-bridges in a prepowerstroke state are poised for actin binding," Biophysical Journal, vol. 85, no. 2, pp. 1063-1079, 2003.

[50] B. C. Tanner, M. Regnier, and T. L. Daniel, "A spatially explicit model of muscle contraction explains a relationship between activation phase, power and ATP utilization in insect flight," Journal of Experimental Biology, vol. 211, no. 2, pp. 180-186, 2008.

[51] K. S. Campbell, "Interactions between connected halfsarcomeres produce emergent mechanical behavior in a mathematical model of muscle," PLoS Computational Biology, vol. 5, no. 11, Article ID e1000560, 2009.

[52] M. Linari, G. Piazzesi, and V. Lombardi, "The effect of myofilament compliance on kinetics of force generation by myosin motors in muscle," Biophysical Journal, vol. 96, no. 2, pp. 583-592, 2009.

[53] R. J. Levine, M. Elfvin, M. M. Dewey, and B. Walcott, "Paramyosin in invertebrate muscles. II. Content in relation to structure and function," Journal of Cell Biology, vol. 71, no. 1, pp. 273-279, 1976.

[54] R. Craig and J. L. Woodhead, "Structure and function of myosin filaments," Current Opinion in Structural Biology, vol. 16, no. 2, pp. 204-212, 2006.

[55] S. L. Hooper, K. H. Hobbs, and J. B. Thuma, "Invertebrate muscles: thin and thick filament structure; molecular basis of contraction and its regulation, catch and asynchronous muscle," Progress in Neurobiology, vol. 86, no. 2, pp. 72-127, 2008.

[56] J. M. Squire, Muscle: Design, Diversity, and Disease, Benjamin/Cummings, Menlo Park, Calif, USA, 1986.

[57] T. Nishizaka, H. Miyata, H. Yoshikawa, S. Ishiwata, and K. Kinosita Jr., "Unbinding force of a single motor molecule of muscle measured using optical tweezers," Nature, vol. 377, no. 6546, pp. 251-254, 1995.

[58] T. Nishizaka, R. Seo, H. Tadakuma, K. Kinosita Jr., and S. Ishiwata, "Characterization of single actomyosin rigor bonds: load dependence of lifetime and mechanical properties," Biophysical Journal, vol. 79, no. 2, pp. 962-974, 2000.

[59] H. Nakajima, Y. Kunioka, K. Nakano, K. Shimizu, M. Seto, and T. Ando, "Scanning force microscopy of the interaction events between a single molecule of heavy meromyosin and actin," Biochemical and Biophysical Research Communications, vol. 234, no. 1, pp. 178-182, 1997.

[60] B. Guo and W. H. Guilford, "Mechanics of actomyosin bonds in different nucleotide states are tuned to muscle contraction," Proceedings of the National Academy of Sciences 
of the United States of America, vol. 103, no. 26, pp. 9844 9849, 2006.

[61] W. M. Obermann, M. Gautel, K. Weber, and D. O. Fürst, "Molecular structure of the sarcomeric $\mathrm{M}$ band: mapping of titin and myosin binding domains in myomesin and the identification of a potential regulatory phosphorylation site in myomesin," EMBO Journal, vol. 16, no. 2, pp. 211-220, 1997.

[62] A. Houmeida, J. Holt, L. Tskhovrebova, and J. Trinick, "Studies of the interaction between titin and myosin," Journal of Cell Biology, vol. 131, no. 6, part 1, pp. 1471-1481, 1995.

[63] G. Ayer and J. O. Vigoreaux, "Flightin is a myosin rod binding protein," Cell Biochemistry and Biophysics, vol. 38, no. 1, pp. 41-54, 2003.

[64] E. Flashman, H. Watkins, and C. Redwood, "Localization of the binding site of the C-terminal domain of cardiac myosinbinding protein-C on the myosin rod," Biochemical Journal, vol. 401, no. 1, pp. 97-102, 2007.

[65] J. A. Suggs, A. Cammarato, W. A. Kronert, et al., "Alternative S2 hinge regions of the myosin rod differentially affect muscle function, myofibril dimensions and myosin tail length," Journal of Molecular Biology, vol. 367, no. 5, pp. 1312-1329, 2007.

[66] M. M. Dewey, B. Walcott, D. E. Colflesh, H. Terry, and R. J. Levine, "Changes in thick filament length in Limulus striated muscle," Journal of Cell Biology, vol. 75, no. 2, part 1, pp. 366380, 1977.

[67] E. M. Nagornyak, F. A. Blyakhman, and G. H. Pollack, "Stepwise length changes in single invertebrate thick filaments," Biophysical Journal, vol. 89, no. 5, pp. 3269-3276, 2005.

[68] M. Cervera, J. J. Arredondo, and R. M. Ferreres, "Paramyosin and miniparamyosin," in Nature's Versatile Engine: Insect Flight Muscle Inside and Out, J. O. Vigoreaux, Ed., pp. 76-85, Springer, New York, NY, USA, 2006.

[69] D. C. White, "The elasticity of relaxed insect fibrillar flight muscle," Journal of Physiology, vol. 343, pp. 31-57, 1983.

[70] P. K. Luther, P. M. Bennett, C. Knupp, et al., "Understanding the organisation and role of myosin binding protein $\mathrm{C}$ in normal striated muscle by comparison with MyBP-C knockout cardiac muscle," Journal of Molecular Biology, vol. 384, no. 1, pp. 60-72, 2008.

[71] M. F. Schmid and H. F. Epstein, "Muscle thick filaments are rigid coupled tubules, not flexible ropes," Cell Motility and the Cytoskeleton, vol. 41, no. 3, pp. 195-201, 1998.

[72] B. K. McConnell, K. A. Jones, D. Fatkin, et al., "Dilated cardiomyopathy in homozygous myosin-binding protein-C mutant mice," Journal of Clinical Investigation, vol. 104, no. 9, pp. 1235-1244, 1999.

[73] B. M. Palmer, B. K. McConnell, G. H. Li, et al., "Reduced cross-bridge dependent stiffness of skinned myocardium from mice lacking cardiac myosin binding protein-C," Molecular and Cellular Biochemistry, vol. 263, no. 1-2, pp. 73-80, 2004.

[74] M. C. Reedy, B. Bullard, and J. O. Vigoreaux, "Flightin is essential for thick filament assembly and sarcomere stability in Drosophila flight muscles," Journal of Cell Biology, vol. 151, no. 7, pp. 1483-1499, 2000.

[75] C. Guzmán, S. Jeney, L. Kreplak, et al., "Exploring the mechanical properties of single vimentin intermediate filaments by atomic force microscopy," Journal of Molecular Biology, vol. 360, no. 3, pp. 623-630, 2006.

[76] F. Qiu, S. Brendel, P. M. Cunha, et al., "Myofilin, a protein in the thick filaments of insect muscle," Journal of Cell Science, vol. 118, no. 7, pp. 1527-1536, 2005.
[77] N. Mücke, L. Kreplak, R. Kirmse, et al., "Assessing the flexibility of intermediate filaments by atomic force microscopy," Journal of Molecular Biology, vol. 335, no. 5, pp. 1241-1250, 2004.

[78] F. Oosawa, "Actin actin bond strength and the conformational change of F-actin," Biorheology, vol. 14, no. 1, pp. 1119, 1977.

[79] F. Oosawa, Y. Maeda, S. Fujime, S. Ishiwata, T. Yanagida, and M. Taniguchi, "Dynamic characteristics of F-actin and thin filaments in vivo and in vitro," Journal of Mechanochemistry \& Cell Motility, vol. 4, no. 1, pp. 63-78, 1977.

[80] M. Linari, I. Dobbie, M. Reconditi, et al., "The stiffness of skeletal muscle in isometric contraction and rigor: the fraction of myosin heads bound to actin," Biophysical Journal, vol. 74, no. 5, pp. 2459-2473, 1998.

[81] C. A. Rebello and R. D. Ludescher, "Differential dynamic behavior of actin filaments containing tightly- bound $\mathrm{Ca}^{2+}$ or $\mathrm{Mg}^{2+}$ in the presence of myosin heads actively hydrolyzing ATP," Biochemistry, vol. 38, no. 40, pp. 13288-13295, 1999.

[82] H. Yoshimura, T. Nishio, K. Mihashi, K. Kinosita Jr., and A. Ikegami, "Torsional motion of eosin-labeled F-actin as detected in the time-resolved anisotropy decay of the probe in the sub-millisecond time range," Journal of Molecular Biology, vol. 179, no. 3, pp. 453-467, 1984.

[83] T. Nishizaka, T. Yagi, Y. Tanaka, and S. Ishiwata, "Righthanded rotation of an actin filament in an in vitro motile system," Nature, vol. 361, no. 6409, pp. 269-271, 1993.

[84] C. E. Schutt and U. Lindberg, "Actin as the generator of tension during muscle contraction," Proceedings of the National Academy of Sciences of the United States of America, vol. 89, no. 1, pp. 319-323, 1992.

[85] R. Jarosch, "Large-scale models reveal the two-component mechanics of striated muscle," International Journal of Molecular Sciences, vol. 9, no. 12, pp. 2658-2723, 2008.

[86] E. Prochniewicz, Q. Zhang, P. A. Janmey, and D. D. Thomas, "Cooperativity in F-actin: binding of gelsolin at the barbed end affects structure and dynamics of the whole filament," Journal of Molecular Biology, vol. 260, no. 5, pp. 756-766, 1996.

[87] C. L. Wang, "Caldesmon and the regulation of cytoskeletal functions," Advances in Experimental Medicine and Biology, vol. 644, pp. 250-272, 2008.

[88] D. H. Heeley, M. H. Watson, A. S. Mak, P. Dubord, and L. B. Smillie, "Effect of phosphorylation on the interaction and functional properties of rabbit striated muscle $\alpha \alpha$ tropomyosin," Journal of Biological Chemistry, vol. 264, no. 5, pp. 2424-2430, 1989.

[89] K.-I. Sano, K. Maeda, T. Oda, and Y. Maéda, "The effect of single residue substitutions of serine-283 on the strength of head-to-tail interaction and actin binding properties of rabbit skeletal muscle $\alpha$-tropomyosin," Journal of Biochemistry, vol. 127, no. 6, pp. 1095-1102, 2000.

[90] V. S. Rao, E. N. Marongelli, and W. H. Guilford, "Phosphorylation of tropomyosin extends cooperative binding of myosin beyond a single regulatory unit," Cell Motility and the Cytoskeleton, vol. 66, no. 1, pp. 10-23, 2009.

[91] E. Prochniewicz, N. Janson, D. D. Thomas, and E. M. De La Cruz, "Cofilin increases the torsional flexibility and dynamics of actin filaments," Journal of Molecular Biology, vol. 353, no. 5, pp. 990-1000, 2005.

[92] B. R. McCullough, L. Blanchoin, J.-L. Martiel, and E. M. De La Cruz, "Cofilin increases the bending flexibility of actin filaments: implications for sSevering and cell mechanics," 
Journal of Molecular Biology, vol. 381, no. 3, pp. 550-558, 2008.

[93] B. Bugyi, G. Papp, G. Hild, et al., "Formins regulate actin filament flexibility through long range allosteric interactions," Journal of Biological Chemistry, vol. 281, no. 16, pp. 1072710736, 2006.

[94] A. S. McElhinny, S. T. Kazmierski, S. Labeit, and C. C. Gregorio, "Nebulin: the nebulous, multifunctional giant of striated muscle," Trends in Cardiovascular Medicine, vol. 13, no. 5, pp. 195-201, 2003.

[95] B. Bullard, C. Burkart, S. Labeit, and K. Leonard, "The function of elastic proteins in the oscillatory contraction of insect flight muscle," Journal of Muscle Research and Cell Motility, vol. 26, no. 6-8, pp. 479-485, 2005.

[96] I. Agarkova and J.-C. Perriard, "The M-band: an elastic web that crosslinks thick filaments in the center of the sarcomere," Trends in Cell Biology, vol. 15, no. 9, pp. 477-485, 2005.

[97] J. O. Vigoreaux, "The muscle Z band: lessons in stress management," Journal of Muscle Research and Cell Motility, vol. 15, no. 3, pp. 237-255, 1994.

[98] A. A. Shabarchin and A. K. Tsaturyan, "Proposed role of the M-band in sarcomere mechanics and mechano-sensing: a model study," Biomechanics and Modeling in Mechanobiology, vol. 9, no. 2, pp. 163-175, 2009.

[99] L. G. Prado, I. Makarenko, C. Andresen, M. Krüger, C. A. Opitz, and W. A. Linke, "Isoform diversity of giant proteins in relation to passive and active contractile properties of rabbit skeletal muscles," Journal of General Physiology, vol. 126, no. 5, pp. 461-480, 2005.

[100] N. Fukuda, T. Terui, S. Ishiwata, and S. Kurihara, "Titinbased regulations of diastolic and systolic functions of mammalian cardiac muscle," Journal of Molecular and Cellular Cardiology, vol. 48, no. 5, pp. 876-881, 2010.

[101] M. Krüger and W. A. Linke, "Titin-based mechanical signalling in normal and failing myocardium," Journal of Molecular and Cellular Cardiology, vol. 46, no. 4, pp. 490-498, 2009.

[102] C. Neagoe, M. Kulke, F. Del Monte, et al., "Titin isoform switch in ischemic human heart disease," Circulation, vol. 106, no. 11, pp. 1333-1341, 2002.

[103] H. L. Granzier and K. Wang, "Interplay between passive tension and strong and weak binding cross-bridges in insect indirect flight muscle: a functional dissection by gelsolin-mediated thin filament removal," Journal of General Physiology, vol. 101, no. 2, pp. 235-270, 1993.

[104] I. A. Telley, J. Denoth, E. Stüssi, G. Pfitzer, and R. Stehle, "Half-sarcomere dynamics in myofibrils during activation and relaxation studied by tracking fluorescent markers," Biophysical Journal, vol. 90, no. 2, pp. 514-530, 2006.

[105] M. A. Geeves and S. S. Lehrer, "Dynamics of the muscle thin filament regulatory switch: the size of the cooperative unit," Biophysical Journal, vol. 67, no. 1, pp. 273-282, 1994.

[106] M. Regnier, A. J. Rivera, C.-K. Wang, M. A. Bates, P. B. Chase, and A. M. Gordon, "Thin filament near-neighbour regulatory unit interactions affect rabbit skeletal muscle steady-state force-Ca ${ }^{2+}$ relations," Journal of Physiology, vol. 540, no. 2, pp. 485-497, 2002.

[107] T. E. Gillis, D. A. Martyn, A. J. Rivera, and M. Regnier, "Investigation of thin filament near-neighbour regulatory unit interactions during force development in skinned cardiac and skeleta muscle," Journal of Physiology, vol. 580, no. 2, pp. 561-576, 2007.

[108] F. Fuchs and D. A. Martyn, "Length-dependent $\mathrm{Ca}^{2+}$ activation in cardiac muscle: some remaining questions," Journal of
Muscle Research and Cell Motility, vol. 26, no. 4-5, pp. 199212, 2005.

[109] G. D’Antona, M. A. Pellegrino, R. Adami, et al., "The effect of ageing and immobilization on structure and function of human skeletal muscle fibres," Journal of Physiology, vol. 552, no. 2, pp. 499-511, 2003.

[110] S. Acharyya, K. J. Ladner, L. L. Nelsen, et al., "Cancer cachexia is regulated by selective targeting of skeletal muscle gene products," Journal of Clinical Investigation, vol. 114, no. 3, pp. 370-378, 2004.

[111] M. J. Toth, D. E. Matthews, P. A. Ades, et al., "Skeletal muscle myofibrillar protein metabolism in heart failure: relationship to immune activation and functional capacity," American Journal of Physiology, vol. 288, no. 4, pp. E685-E692, 2005.

[112] M. S. Miller, P. Vanburen, M. M. Lewinter, et al., "Mechanisms underlying skeletal muscle weakness in human heart failure: alterations in single fiber myosin protein content and function," Circulation, vol. 2, no. 6, pp. 700-706, 2009.

[113] H. W. Van Hees, H. F. Van Der Heijden, C. A. Ottenheijm, et al., "Diaphragm single-fiber weakness and loss of myosin in congestive heart failure rats," American Journal of Physiology, vol. 293, no. 1, pp. H819-H828, 2007.

[114] C. A. Ottenheijm, L. M. Heunks, T. Hafmans, et al., "Titin and diaphragm dysfunction in chronic obstructive pulmonary disease," American Journal of Respiratory and Critical Care Medicine, vol. 173, no. 5, pp. 527-534, 2006.

[115] L. Larsson, X. Li, L. Edstrom, et al., "Acute quadriplegia and loss of muscle myosin in patients treated with nondepolarizing neuromuscular blocking agents and corticosteroids: mechanisms at the cellular and molecular levels," Critical Care Medicine, vol. 28, no. 1, pp. 34-45, 2000.

[116] F. Haddad, R. R. Roy, H. Zhong, V. R. Edgerton, and K. M. Baldwin, "Atrophy responses to muscle inactivity. I. Cellular markers of protein deficits," Journal of Applied Physiology, vol. 95, no. 2, pp. 781-790, 2003.

[117] M. S. Miller, P. Lekkas, J. M. Braddock, et al., "Aging enhances indirect flight muscle fiber performance yet decreases flight ability in Drosophila," Biophysical Journal, vol. 95, no. 5, pp. 2391-2401, 2008.

[118] M. H. Dickinson and J. R. Lighton, "Muscle efficiency and elastic storage in the flight motor of Drosophila," Science, vol. 268, no. 5207, pp. 87-90, 1995.

[119] C. P. Ellington, "The aerodynamics of hovering insect flight.VI. Lift and power requirements," Philosophical Transactions of the Royal Society of London Series B, vol. 305, no. 1122, pp. 145-181, 1984.

[120] D. Frank, C. Kuhn, H. A. Katus, and N. Frey, "The sarcomeric Z-disc: a nodal point in signalling and disease," Journal of Molecular Medicine, vol. 84, no. 6, pp. 446-468, 2006.

[121] N. D. Epstein and J. S. Davis, "Sensing stretch is fundamental," Cell, vol. 112, no. 2, pp. 147-150, 2003.

[122] M. Hoshijima, "Mechanical stress-strain sensors embedded in cardiac cytoskeleton: $\mathrm{Z}$ disk, titin, and associated structures," American Journal of Physiology, vol. 290, no. 4, pp. H1313-H1325, 2006.

[123] U. Nongthomba, M. Cummins, S. Clark, J. O. Vigoreaux, and J. C. Sparrow, "Suppression of muscle hypercontraction by mutations in the myosin heavy chain gene of Drosophila melanogaster," Genetics, vol. 164, no. 1, pp. 209-222, 2003.

[124] K. Vijayan, J. L. Thompson, K. M. Norenberg, R. H. Fitts, and D. A. Riley, "Fiber-type susceptibility to eccentric contraction-induced damage of hindlimb-unloaded rat $\mathrm{AL}$ muscles," Journal of Applied Physiology, vol. 90, no. 3, pp. 770-776, 2001. 
[125] E. P. Debold, J. Romatowski, and R. H. Fitts, "The depressive effect of Pi on the force-pCa relationship in skinned single muscle fibers is temperature dependent," American Journal of Physiology, vol. 290, no. 4, pp. C1041-C1050, 2006.

[126] S. Lange, I. Agarkova, J.-C. Perriard, and E. Ehler, "The sarcomeric M-band during development and in disease," Journal of Muscle Research and Cell Motility, vol. 26, no. 68, pp. 375-379, 2005.

[127] A. Weiss, S. Schiaffino, and L. A. Leinwand, "Comparative sequence analysis of the complete human sarcomeric myosin heavy chain family: implications for functional diversity," Journal of Molecular Biology, vol. 290, no. 1, pp. 61-75, 1999.

[128] J. M. Squire, T. Bekyarova, G. Farman, et al., "The myosin filament superlattice in the flight muscles of flies: a-band lattice optimisation for stretch-activation?" Journal of Molecular Biology, vol. 361, no. 5, pp. 823-838, 2006.

[129] S. Trachtenberg and I. Hammel, "The rigidity of bacterial flagellar filaments and its relation to filament polymorphism," Journal of Structural Biology, vol. 109, no. 1, pp. 1827, 1992.

[130] R. W. Kensler, "The mammalian cardiac muscle thick filament: backbone contributions to meridional reflections," Journal of Structural Biology, vol. 149, no. 3, pp. 313-324, 2005.

[131] M. D. Goode, "Ultrastructure and contractile properties of isolated myofibrils and myofilaments from drosophila flight muscle," Transactions of the American Microscopical Society, vol. 91, no. 2, pp. 182-194, 1972.

[132] E. Oroudjev, J. Soares, S. Arcdiacono, J. B. Thompson, S. A. Fossey, and H. G. Hansma, "Segmented nanofibers of spider dragline silk: atomic force microscopy and single-molecule force spectroscopy," Proceedings of the National Academy of Sciences of the United States of America, vol. 99, supplement 2, pp. 6460-6465, 2002.

[133] E. Di Cola, T. A. Waigh, J. Trinick, et al., "Persistence length of titin from rabbit skeletal muscles measured with scattering and microrheology techniques," Biophysical Journal, vol. 88, no. 6, pp. 4095-4106, 2005.

[134] M. S. Z. Kellermayer, C. Bustamante, and H. L. Granzier, "Mechanics and structure of titin oligomers explored with atomic force microscopy," Biochimica et Biophysica Acta, vol. 1604, no. 2, pp. 105-114, 2003.

[135] A. Nagy, L. Grama, T. Huber, et al., "Hierarchical extensibility in the PEVK domain of skeletal-muscle titin," Biophysical Journal, vol. 89, no. 1, pp. 329-336, 2005.

[136] Z.-P. Luo, Y.-L. Sun, T. Fujii, and K.-N. An, "Single molecule mechanical properties of type II collagen and hyaluronan measured by optical tweezers," Biorheology, vol. 41, no. 3-4, pp. 247-254, 2004.

[137] Y.-L. Sun, Z.-P. Luo, A. Fertala, and K.-N. An, "Stretching type II collagen with optical tweezers," Journal of Biomechanics, vol. 37, no. 11, pp. 1665-1669, 2004.

[138] B. Bullard, T. Garcia, V. Benes, M. C. Leake, W. A. Linke, and A. F. Oberhauser, "The molecular elasticity of the insect flight muscle proteins projectin and kettin," Proceedings of the National Academy of Sciences of the United States of America, vol. 103, no. 12, pp. 4451-4456, 2006.

[139] A. N. Round, M. Berry, T. J. McMaster, et al., "Heterogeneity and persistence length in human ocular mucins," Biophysical Journal, vol. 83, no. 3, pp. 1661-1670, 2002.

[140] C. Rivetti, M. Guthold, and C. Bustamante, "Scanning force microscopy of DNA deposited onto mica: equilibration versus kinetic trapping studied by statistical polymer chain analysis," Journal of Molecular Biology, vol. 264, no. 5, pp. 919-932, 1996.

[141] C. P. Brangwynne, G. H. Koenderink, E. Barry, Z. Dogic, F. C. MacKintosh, and D. A. Weitz, "Bending dynamics of fluctuating biopolymers probed by automated highresolution filament tracking," Biophysical Journal, vol. 93, no. 1, pp. 346-359, 2007.

[142] R. Duggal and M. Pasquali, "Dynamics of individual singlewalled carbon nanotubes in water by real-time visualization," Physical Review Letters, vol. 96, no. 24, Article ID 246104, 2006.

[143] F. Pampaloni, G. Lattanzi, A. Jonáš, T. Surrey, E. Frey, and E.-L. Florin, "Thermal fluctuations of grafted microtubules provide evidence of a length-dependent persistence length," Proceedings of the National Academy of Sciences of the United States of America, vol. 103, no. 27, pp. 10248-10253, 2006. 

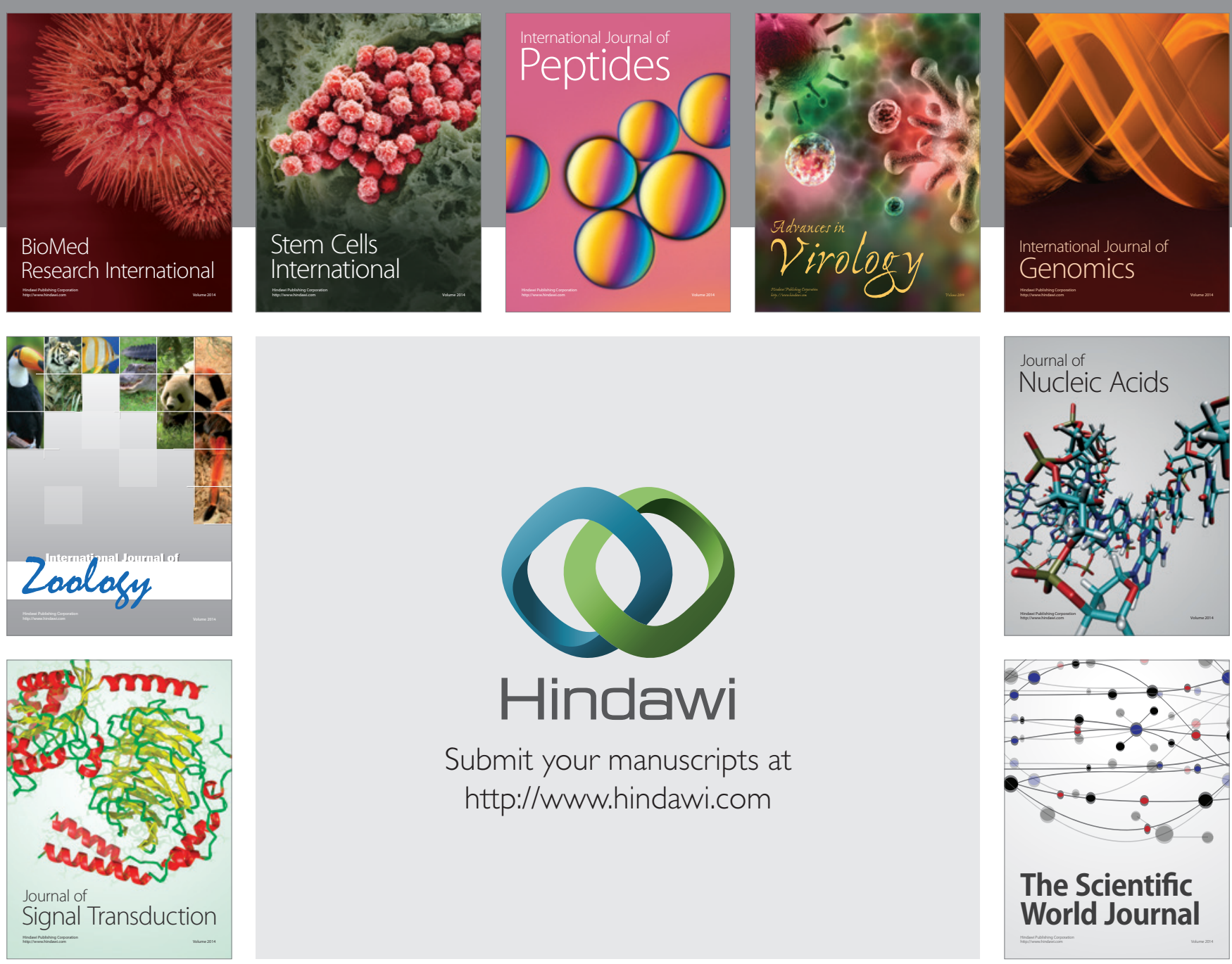

Submit your manuscripts at

http://www.hindawi.com
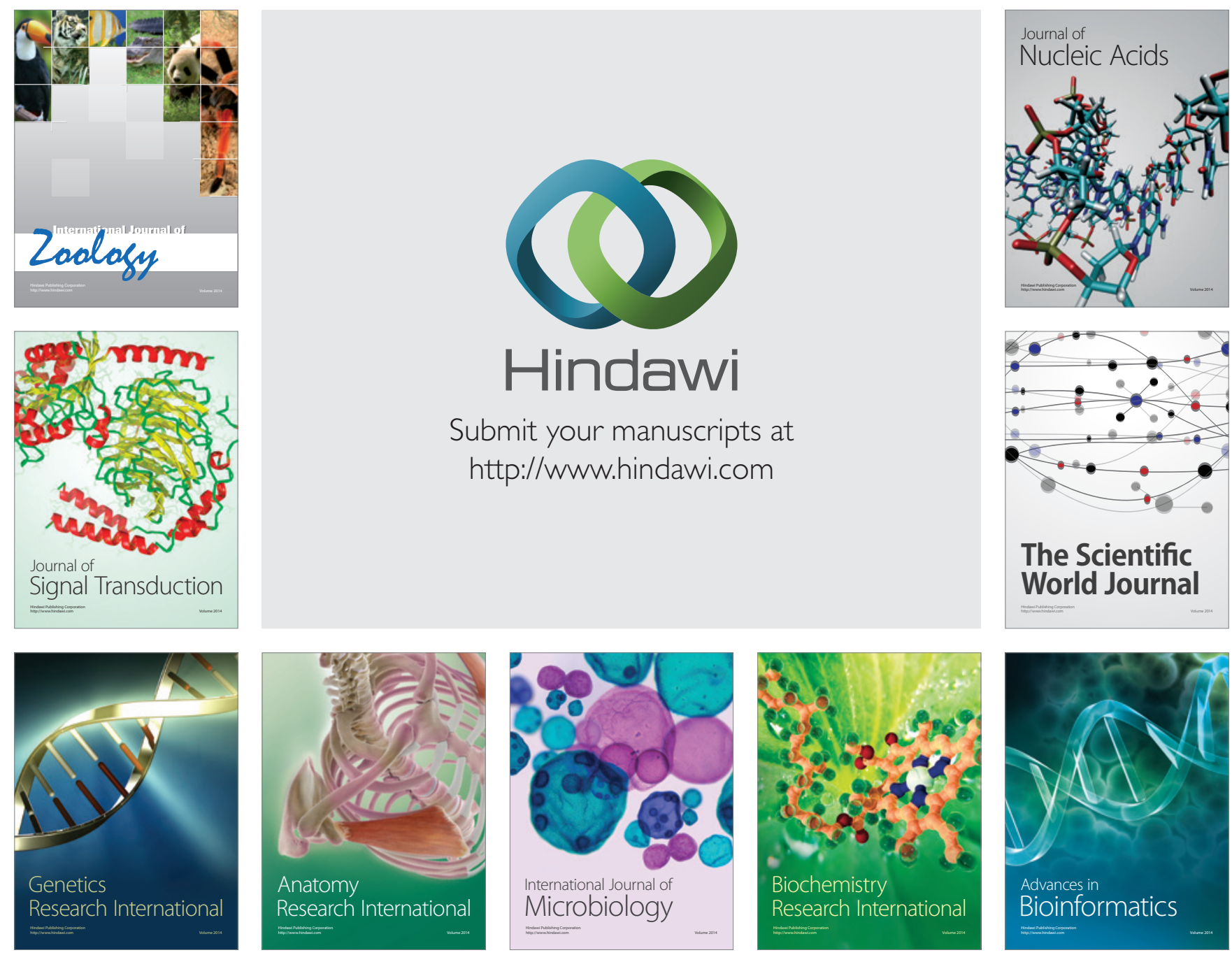

The Scientific World Journal
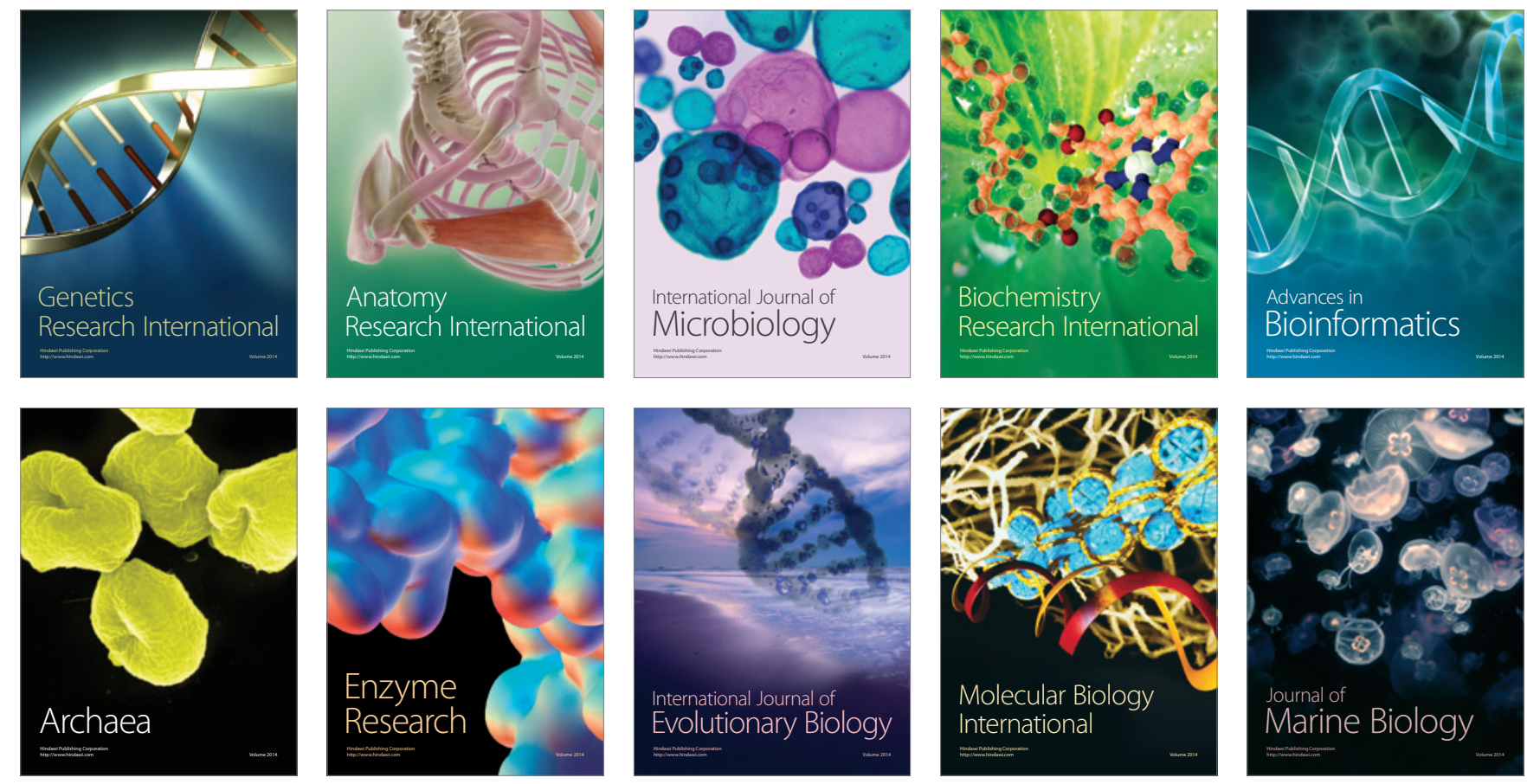